\title{
Study on the Third Industrial Revolution and Paradigm Transformation of China's Manufacturing Industry-Based on Theoretical Analysis of Scale Economy and Scope Economy
}

\author{
Xiaowen Zeng \\ College of Economics, Jinan University, Guangzhou, China \\ Email: 101215354@qq.com
}

Received 19 January 2016; accepted 12 February 2016; published 15 February 2016

Copyright (C) 2016 by author and Scientific Research Publishing Inc.

This work is licensed under the Creative Commons Attribution International License (CC BY). http://creativecommons.org/licenses/by/4.0/

(c) (i) Open Access

\begin{abstract}
After the US subprime mortgage crisis in 2008, European and American developed countries have deepened "the third industrial revolution" characterized by intelligence, digitization and individualization in the global market, so as to promote their industry. This brand-new industrial revolution tide will deeply change the paradigm of traditional manufacturing industry. Through the extensive application of advanced manufacturing technology like 3D print technology, flexible production technology and reconfigurable production system, the importance of large-scale standardized production under the guidance of scale economy in modern market declines gradually, and more and more attention is paid to the scope economy idea that can adapt to the market rapidly and satisfy consumers' individualized needs. By analyzing the trend and essence of the third industrial revolution, this paper expounds the impacts that might be caused to Chinese traditional manufacturing industry, such as the reduction of labor cost advantage, localization and decentralization of production mode, gradual deepening of service degree in manufacturing industry, and suppression on the traditional industry upgrading path and industrialization process. Meanwhile, based on the analysis of scale economy and scope economy, the ideological transformation from scale economy to scope economy is further proposed; theoretical analysis is made for the applicability of these two under the environment of the third industrial revolution, and the theoretical basis and development direction for paradigm transformation of Chinese manufacturing industry in the future are pointed out.
\end{abstract}

\section{Keywords}

Paradiam Transformation, Chinese Manufacturing Industry, Production Mode 


\section{Introduction}

Since 2010, China's manufacturing output has overtaken the US, becoming the biggest manufacturing country all over the world. However, after the US subprime mortgage crisis in 2008, the European and American developed countries have implemented a series of industrial revitalization plan, which means that a third industrial revolution with the characteristics of personalization, intelligence and digital in the global market continued to deepen. In such a new wave of industrial revolution, Chinese traditional manufacturing industry is facing huge impact, such as the gradually decreasing labor cost advantages, mode of production localization and diversification and deepening manufacturing service level, etc. In order to achieve a new round of growth and success for industry transformation, manufacturing revolution in China is urgently needed. Based on the key historical period, this paper puts forward the new direction for transformation of Chinese manufacturing paradigm - "manufacturing individuation", pointing out that the size of its core content is from the traditional economic paradigm to the scope economy. At the same time, through the theoretical analysis of traditional scale economies and scope economy for its applicability, it is pointed out that with the use of a large number of advanced manufacturing crafts, enterprises average cost curve is flatting, and the importance of personalized customization in today's market is increasingly prominent. What's more, the traditional large-scale standardized production to reduce the enterprise cost function will be no longer obvious, and the importance of economies of scale in the modern market will decline. On the other hand, through the analysis of the current market supply and demand, the effect of quick market to meet the personalized needs of consumers of the scope of the economy in the third industrial revolution wave will be even more popular, and the scope economy will bring manufacturers to reduce production costs and improve product differentiation, even promoting the marketing and enterprise technology innovation and competitive advantage. Finally the essay proposed that compared to traditional standardized mass production, new manufacturing paradigm based on the scope economy could be more adaptable to the current market demand, and promote a country’s economic growth.

\section{Trend and Essence of the Third Industrial Revolution}

\subsection{Current Situations about Reform and Development of Modern Manufacturing Industry}

When the international financial crisis triggered by the US subprime mortgage crisis fades away, people begin to reflect on such new-type international financial crisis, especially European and American developed countries deeply encumbered by this financial crisis. At present, major developed countries in the world have realized that the production capacity and knowledge accumulation contained by manufacturing industry are related to the long-term development performance of economy in a country. The strategy of manufacturing industry-oriented entity economy is not only shown in the economic value directly created by the department but also reflected in its long-term driving effect on national economy. Therefore, these developed countries have introduced the socalled "re-industrialization" one after another, such as "manufacturing renaissance plan" of US and "future factory plan" of Europe. Such industrial recovery plans are not simply equal to "re-industrialization". Western developed countries can hardly form effective competitive advantages in the aspects of traditional manufacturing industry elements covering labor cost, professional and technical personnel, and market size. Therefore, they are at a disadvantage in the international trade with developing countries. According to David Ricardo's [1] comparative advantage theory, with the pre condition that there are differences existing in labor productivity between two countries, which are capable of producing two commodities engage in the free market, then each country's overall consumption will go up by exporting the good for which it has a comparative advantage while importing the other good. Ricardo's theory also indicates that it is the comparative advantage responsible for most of the international trade instead of absolute advantage. Therefore, it is quite difficult for Western developed countries to guide the return of overseas factories again.

HUANG Yanghua and ZHUO Lihong [2] pointed out that the so-called "re-industrialization" and "industrial recovery" meant to drive the development of manufacturing industry via the breakthrough of advanced manufacturing technology and to build new comparative advantages of competition for manufacturing industry. The core content is to accelerate and promote the application of advanced manufacturing technology like artificial intelligence, digital manufacturing, 3D print and industrial robot, and to guide the global industrial production system to develop toward individualization, automation and intelligence that will help Western developed coun- 
tries gain technology and resource advantages by utilizing the technical advantages accumulated by developed countries in information, communication and technology fields for a long time. At present, due to such an individualization, automation and intelligence reform of manufacturing industry under the drive of extensive use of emerging technology, people have realized that a new industrial reform tide is being formed - " the third industrial revolution”.

\subsection{Core Content of the Third Industrial Revolution}

For the definition and connotation of "the third industrial revolution", opinions still vary in different circles and the following two viewpoints are the main sources. The first viewpoint is "communication and energy theory" proposed by the US scholar Rifkin [3] in The Third Industrial Revolution. He considered that all industrial revolutions in human history were important changes triggered by the combination of communication technology and energy technology. For instance, in the 19th century, owing to the combination of communication media including newspaper, periodicals, magazines and books with steam engine setting coal as the energy, people entered the age of steam, and the first industrial revolution arrived. In the 20th century, the combination of communication media including telephone and wireless communication with oil engine led people to walk into the electrical age, and the second industrial revolution was triggered. Now with the continuous development of the new communication technology internet, renewable energy sources have entered people's daily life gradually. The combination of internet with new energy is about to cause the third industrial revolution around the world. The second viewpoint is "production mode theory" proposed by Markillie [4] in The Economist. He considered that industrial revolution mainly referred to the revolution reflected in production technology and production mode. In the first industrial revolution, machine production replaced manual workshop, and mechanized factory system became the dominant production organization form. In the second industrial revolution, assembly line production created by automation made large-scale production become the dominant production mode. In the third industrial revolution that is happening now, the core is digital production, individualized production and intelligent production, and the new production mode will make the large-scale assembly line production mode become a history. Meanwhile, individualized manufacturing closer to the consumer market with fast reaction characteristic will be become a brand-new production mode. In my opinion, no matter how the third industrial revolution is defined, the future development trend of manufacturing industry is undoubtedly certain. With the integration of information technology and production \& service fields, industrial production will be transformed into digitization, networking and intelligence, and the production mode will also develop toward individualized, distributed and local production. Meanwhile, the third industrial revolution is not simple revolution of production mode and production technology, and its essence is the transformation of economic development idea. It will be transformed from scale economy aiming to be bigger and stronger into scope economy aimed at high efficient utilization of resources. On the one hand, when fundamental changes happen to productivity conditions, the multi-purpose nature of resources will be discovered endlessly, exclusiveness of assets will decline, and scale advantage will weaken gradually. On the other hand, with the continuous increase of people's income level, consumer demand also experiences fundamental changes. The simple material need is transformed into nonmaterial need. Consumption aims to not only meet physiological needs but also satisfy psychological needs. "Diversification, individualization and differentiation" have become essential characteristics of demand. The change of demand not only hastens flexible production system and guides "small-amount and multi-variety" production mode to occupy the status of mainstream production mode but also makes differentiation become the starting point and objective of enterprises or regions when they seek scope economy. It is easy to see that the tide of economic growth pattern revolution is rising in the world, and quantitative expansion is changed into quality growth. Compared with assembly line and standard production under the traditional scale economy, scope economy has more extensive applicability.

\section{Impacts of the Third Industrial Revolution on China's Manufacturing Industry}

Faced with such a new industrial production mode revolution, either developed countries or developing countries will experience opportunities and challenges at the same time. It becomes a hot topic discussed by various circles in the society to grasp the development opportunity in such a new industrial revolution tide and to find a new economic growth pattern. China is faced with multiple challenges. Since reform and opening up, Chinese economy has increased rapidly and its economic strength has been enhanced quickly. It has become the world's 
second largest economy second only to the US by surpassing Japan. Its GDP has maintained growth at the rate of about $10 \%$ for 30 consecutive years. In recent years, the growth rate slows down, but the growth rate is still approximate to $8 \%$. However, if we still stick to the traditional economic development pattern, these economic growth miracles might disappear in the tide of the third industrial revolution. Therefore, faced with the upcoming third industrial revolution, we should hold sense of crisis and sense of urgency. Firstly, we must realize which challenges it will bring about to economic growth in China.

1) Decline of labor cost advantage

With the digitization and intelligence of manufacturing process in the third industrial revolution, numerous traditional simple workers will be replaced by a few knowledge employees, and the proportion of labor cost in the whole production cost will decline gradually. Therefore, the labor cost advantage of China will be weakened little by little. In the current global trading market, a large amount of cheap labor force is the major comparative advantage in foreign trade of China. However, with the further application of advanced manufacturing technology, the proportion of labor in the total investment is bound to decrease. Then in international competition, the comparative advantage of cheap labor force possessed by China will disappear gradually. In recent years, the growth rate of labor cost rises obviously in China, and the growth rate is greatly higher than that of developed countries. According to the research of HUANG Qunhui [5], from 2000 to 2009, the annual average growth rate of hourly wage of Chinese workers in dollar was 13.7\%; as for developed countries in the same period, it was $3.3 \%$ in the US, $4.5 \%$ in Britain, 6.6\% in Germany, 7.9\% in France, and 8.7\% in Australia. Obviously, the "re-industrialization" and "industrial recovery plan" guided by developed countries will trigger counter-transference of manufacturing industry from developing countries to developed countries in the future. Faced with such counter-transference, if we still rely on the traditional economic growth pattern and attract foreign investment by utilizing China's cheap labor force, we will be at a disadvantage gradually in international competition with the continuous introduction of advanced manufacturing technology. Numerous laborers will be faced with unemployment, and economic growth will slow down and even degrade. Finally, we will fall behind developed countries again in the tide of the third industrial revolution.

2) Localization and decentralization of production mode

Due to the further deepening of globalization, the boundary among countries in the market becomes vaguer and vaguer. On the one hand, global enterprises participate in contending for the global market, so product quality, uniqueness and flexibility will become prominent gradually in competition. On the other hand, consumers become more and more captious and often pursue individualized products, so upgrading of products is faster and faster, and the production cycle becomes shorter and shorter. Consumer demand has already been transformed from large scale in the past into anti-popularization and even individualized development. Moreover, the application of reconfigurable production system, 3D print technology and additive manufacturing technology in modern manufacturing industry has further promoted this development trend. Therefore, in order to approach the market more and to gain closer interaction with consumers, the function of large enterprises declines gradually, and innovative middle and small-sized enterprises play a more and more important role. The new production mode presents characteristics of localization and decentralization. FENG Fei [6] considered that this would form a challenge for Chinese industrial system still relying on large-scale export. Due to digital manufacturing, scale economy of many industries will not be obvious anymore, and personalized customization and dispersed manufacturing become the new characteristics. In order to approach the market more, to be closer to domestic consumers, and to react to the market more rapidly, foreign merchants building factories in China will get their fund back and invest in their own countries, so as to conduct local production. Products of overseas innovative middle and small-sized enterprises are more individualized, which will also bring about huge challenges to China's standardized products depending on scale economy and mass production.

3) Gradual deepening of service degree in manufacturing industry

With the promotion of intelligent technology, consumers began to participate in product design and production process gradually; in this way, product design and manufacturing should be closer to consumers' individualized needs; meanwhile, product design, development, manufacturing and use would be combined more closely, and the previous linear process development would be replaced by integration process. Just as mentioned above, small-scale and decentralized production mode will cause further changes to production organization form. For instance, by applying advanced 3D print technology, individualized production will carry out "micro-manufacturing" and "individual business" by setting individual and family as the unit. This is mutual fusion of manufacturing industry and service industry, and the service trend of manufacturing industry is further intensified. At 
present, in order to expand domestic demand and promote economic development, China excessively emphasizes the increase of service industry proportion. However, it ignores the huge driving effect of manufacturing industry in the future development, and neglects the service trend of manufacturing industry. If the development strategy of Chinese manufacturing industry and service industry is not adjusted in time and the service degree of Chinese manufacturing industry is not improved timely, Chinese industrialization process might be unable to gain further breakthroughs for quite a long time in the future.

4) Suppression on the traditional industry upgrading path and industrialization process

According to traditional industrial economics theory, as a backward country, China should develop laborintensive industry and occupy the bottom of smiling curve by undertaking the industrial transfer of developed countries through its comparative advantage. Moreover, it should develop toward both ends of "smiling curve" gradually through imitative innovation and original innovation of products, so as to realize upgrading and surpassing in technology and industry. However nowadays, with the application of advanced technology, manufacturing link and production efficiency of developed countries are improved gradually. For example, when reconfigurable production system is applied, the production cost will maintain a fixed level rather than increase with the output. In this way, developed countries can not only occupy both ends of the industrial value chain but also form competitive advantages in the whole industry chain. HUANG Qunhui and HE Jun [7] pointed out that with the gradual deepening of the third industrial revolution, due to the individualized consumer demand and digital and intelligent manufacturing technology, the product manufacturing link would be as important as research and development and marketing links. In another word, "smiling curve" might not "smile" anymore, and it would even turn into "silent curve". Enterprises and factories moving to overseas developing countries to reduce production cost might go back to developed countries with advanced manufacturing technology due to the application of advanced manufacturing technology and labor cost rise in developing countries. The traditional industry upgrading path will be suppressed in China, and the original industrial paths surpassing developed countries will also be affected. Therefore, the industrialization process will be forced to slow down.

With the gradual weakening of labor cost, localization and decentralization of production mode, increasing deepening of manufacturing industry service degree, and gradual suppression on the traditional industry upgrading path, the effect of traditional economic development mode and manufacturing paradigm on economic growth might not be significant anymore. For instance, as the core achievement of the second industrial revolution-mass production, the content is to conduct assembly line production via specialized equipment, to reduce production cost by utilizing scale economy of production, and to increase the product quality at the same time. Mass production has resulted in explosive growth of industrial capacity and supply capacity. However at present, in the traditional industrial market with numerous standard and large-scale products, consumers pay more and more attention to product differentiation, individualized market requirement becomes more and more important, and the contradiction between scale economy and product differentiation is more and more prominent. Therefore, in the modern market of free competition, scale economy is not the only choice of enterprises, and scope economy becomes more important. It can endow enterprises with the ability of reacting to the market rapidly, so as to respond to consumers' individualized needs. Faced with various challenges, a great revolution of economic growth pattern around the world is brewed. Just as mentioned above, economic growth is transformed from quantitative expansion into quality growth, and more and more attention is paid to scope economy. Can scope economy adapt to the new economic development pattern in developing countries like China? Will a new round of economic growth be brought about to us? Is scale economy inapplicable? This paper will further analyze the above questions.

\section{Theoretical Analysis on Applicability of Scale Economy}

Scale economy in Microeconomics means to form an economy that makes the long-term average cost of output in an enterprise or region decrease with the increase of output by reducing unit output cost in the enterprise or region due to the enhancement of professional level caused by labor division under a certain production technology condition. The theoretical basis of scale economy lies in inseparability of resources, exclusiveness of assets and explicitness of sunk cost. It highlights profession, and tries to increase the efficiency and benefit of economic activities by enhancing profession.

\subsection{Micro-Level}

Originating from the US, scale economy theory reveals the economic scale of mass production. Typical repre- 
sentatives include Alfred Marshall, Chamberlain, Robinson and Bain.

In Principles of Economics, Marshall put forward, "The benefit of mass production can be clearly seen in industry-The benefit of factories lies in: use and reform of special agencies, purchase and selling, and further division of special technology and management work.” Besides, Marshall expounded two approaches of forming scale economy, i.e. "internal scale economy" formed by relying on full and effective utilization, organization and operation efficiency increase of some enterprises for resources, and "external scale economy" formed by relying on reasonable labor division and combination of multiple enterprises as well as reasonable regional layout. He further studied the change rule of scale economy returns. With the continuous expansion of production scale, the scale returns will experience three stages covering increase of scale returns, invariability of scale returns, and decrease of scale returns. However, enterprise scale cannot be expanded endlessly, and it should not be too large. Too large enterprise scale will result in too high management cost, diseconomy of production, increase of cost, and diseconomy of scale.

How to determine the appropriate scale for enterprises? Neoclassical economics further explains scale economy through average cost curve. See Figure 1 when technological progress is not considered.

Short-term average cost curve reflects the change rule of average cost (i.e. unit product cost) when production capacity remains unchanged in a certain period. In the figure, SAC1, SAC2 and SAC3 represent short-term average cost curves of different scales. Average cost decreases with the increase of output, and then rises with the increase of output when it exceeds a certain limit. Long-term average cost curve (LAC) shows the change rule of average cost in the process of increasing production capacity, and it is the envelope curve of short-term average cost curve. When the curve slopes down, it means scale economy. In the figure, is the long-term average cost will decline to point $\mathrm{B}$; it is at the floor level between $\mathrm{B}$ and $\mathrm{C}$, and rises above point $\mathrm{C}$. Therefore, $\mathrm{BC}$ can be called "optimal scale interval", scale at point B is called "minimum optimal scale", and scale at point C is known as "maximum optimal scale". Enterprise scale at any point in this "interval" appropriate.

However in real economy, the increase of production capacity is often driven by technological progress, enterprises will adopt new technology with higher efficiency when increasing the production capacity. Therefore, when the factor of technological progress is considered (it is acknowledged that increase of production capacity and technological progress happen at the same time), in an ordinary way, long-term average cost curve driven by technological progress declines continuously, but the decrease range will drop with the increase of potential exploitation difficulty. Therefore, the long-term average cost curve is adjusted correspondingly, as shown in Figure 2.

No matter whether technological progress is considered, the application of scale economy should be able to effectively reduce average cost of enterprises and to lower production cost. However, with the arrival of the third industrial revolution, various kinds of advanced manufacturing technology will be applied. Here 3D print technology will be taken as an example. SUN Bolin [8] pointed out that 3D print technology meant to complete a series of digital slices via computer aided design technology. Meanwhile, information about these slices will

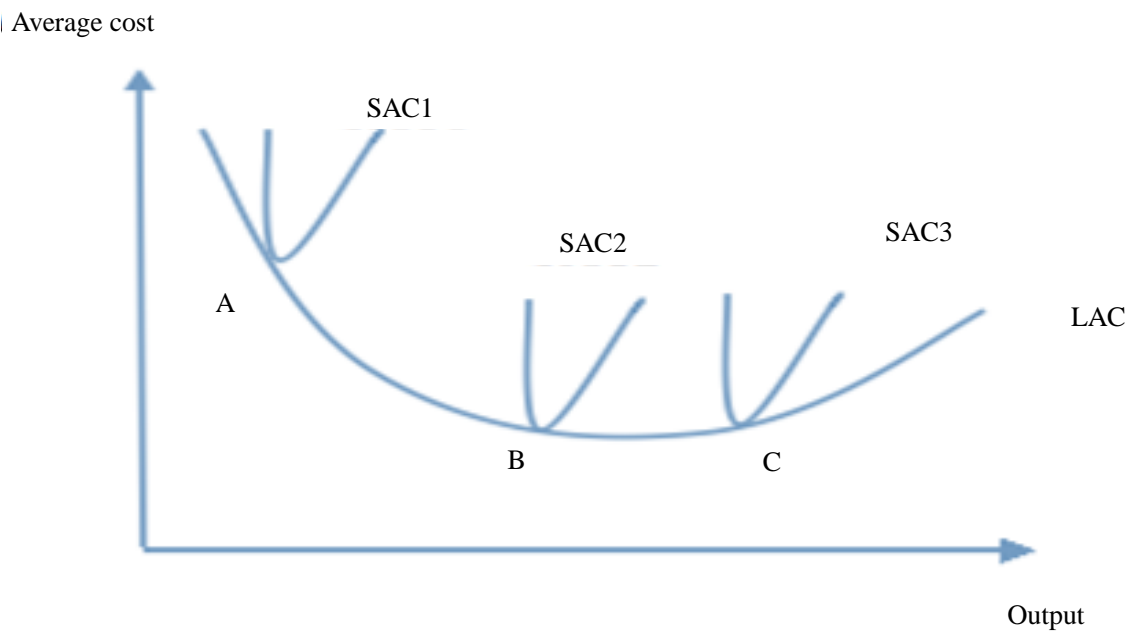

Figure 1. Average cost curve of enterprises (technological progress is not considered). 
be transferred to a 3D printer, and the latter will pile consecutive thin layers through hierarchical processing till a solid object is formed. Its working principle is almost the same with common printers. It is connected to a computer, and "printing materials" will be piled layer by layer via computer control. Finally, the blueprint in computer will be changed into an object. Such new manufacturing technology might make the production cost of single product equal to the unit product cost of mass production. See Figure 3.

\subsection{Macro-Level}

From the macro angle, scale economy will help to increase market competitiveness of enterprises and industries, and thus to enhance international competitive ability of countries. In order to enter the world powers, China has to develop economy and to improve its economic strength. We should not only step toward the international market but also occupy a certain position on the international economic stage. Especially after entering WTO, China has to meet the challenge of "competition internationalization", so world-class enterprises and enterprise groups with strong power and competitive capacity must be established.

However, we should clearly realize that with the further deepening of the third industrial revolution, the mode of attracting consumers by relying on expansion of production scale and reduction of product cost is not suitable for enterprises if they want to gain a success, to survive in the international market with fierce competition, and to stand out. Now consumers need individualized, diversified and differentiated products, and they are willing to purchase personalized products at a higher price rather than cheap products from standardized production. Due to advanced manufacturing technology like intelligent manufacturing system, reconfigurable manufacturing system and flexible production in developed countries, manufacturing industry has entered a brand-new production stage. Individualized customized production satisfying each consumer's needs becomes possible. In developing countries like China, large enterprises that adopt mass production by depending on the comparative

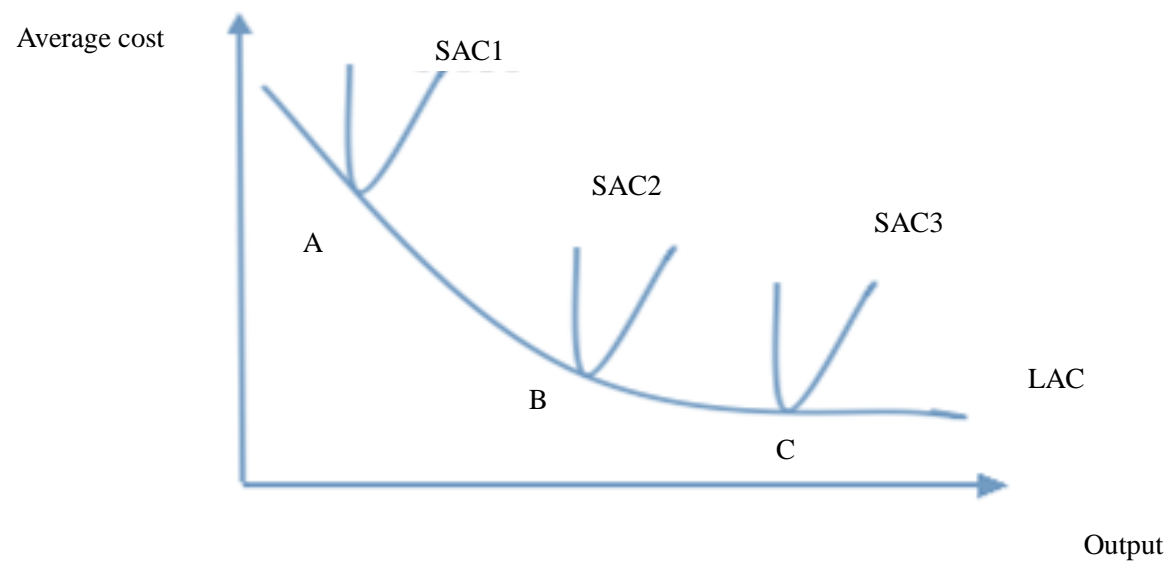

Figure 2. Average cost curve of enterprises (technological progress is considered).

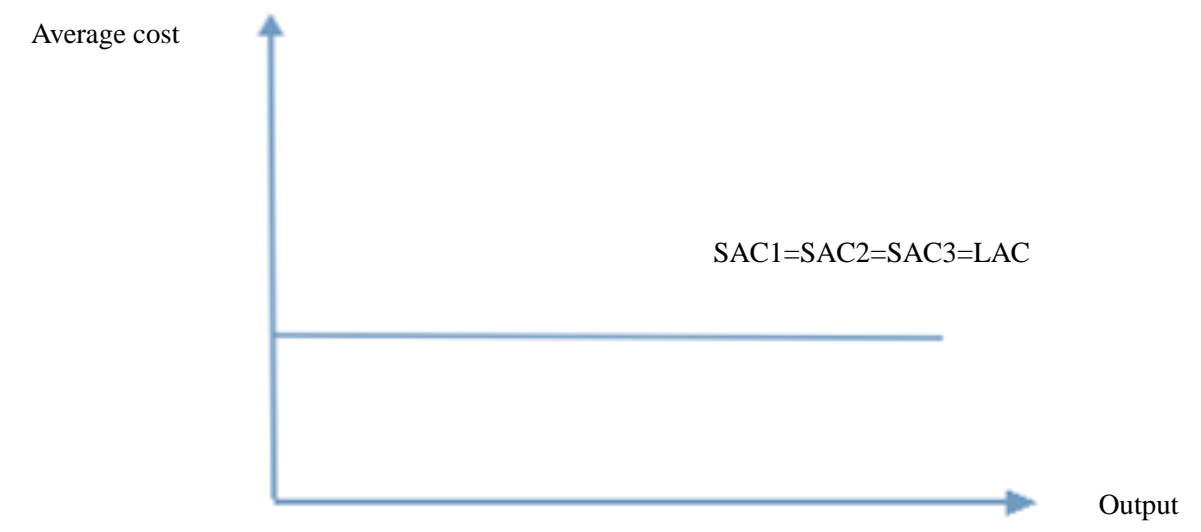

Figure 3. Average cost curve of enterprises (scope economy). 
advantage of low labor cost will be faced with the dilemma of being eliminated again. Therefore, when the effect of scale economy is not obvious anymore, will scope economy guide the new round of economic growth?

\section{Theoretical Analysis on Applicability of Scope Economy}

Scope economy was the economy that the long-term average cost of output tended to decline with the increase of output categories as well as the phenomena like efficient utilization of resources brought about by the synergistic effect of diversified economic activities or economic activity cost saving caused by resource sharing of diversified economic activities. Different from scale economy, scope economy mainly originates from multi-purpose nature of resources and sharing of resource utilization cost. Traditional scope economy in a narrow sense means that the total output of a single enterprise exceeds the total output that can be realized by two enterprises of manufacturing the same product. SHEN Qianqian [9] put forward that scope economy in a broad sense referred to the benefit brought about to the single enterprise when multiple enterprises in the same region manufactured multiple related products, i.e. aggregation effect; this was the external economics of scope economy or the regional scope economy. In this paper, discussion is mainly conducted from scope economy in a broad sense.

In a market of free competition, traditional economics theory tells us that the supply-demand relationship of commodities plays a decisive role. Various changes of the market also come from the interaction between suppliers and demanders. Therefore, this paper will analyze the applicability of scope economy from market suppliers and demanders when considering the applicability of scope economy.

\subsection{Suppliers}

With the continuous improvement of technology, consumer demand changes with each passing day, product categories become more and more diversified, and the market life cycle is shorter and shorter. Dedicated manufacturing system under the traditional mass manufacturing paradigm often has problems like excess production capacity and excessively long development cycle. Due to the high fixed cost and lack of flexible production system, such single production system has lost its rationality gradually. In order to adapt to the highly dynamic product market at present, product suppliers do not need the traditional assembly line production or blind expansion of their production scale. Instead, they require a kind of production that has stronger applicability and flexibility, that can closely respond to the changes of consumer demand, that can manufacture products needed by consumers, and that will realize full life circle products. Undoubtedly, new requirements will be raised for product supply chain and product suppliers. "Supply chaining" of the US retailer leader Wal-Mart mentioned by the US scholar Thomas Friedman [10] in The World Is Flat shows the power of scope economy for us. In the distribution center of Wal-Mart, boxes with commodities acquired from different suppliers will be sent to conveyor belts with different sizes; the electric eye system will scan the bar code on each box and classify them again according to different contents. Then they will be sent to exclusive trucks assigned by various Wal-Mart stores, and transported to the goods shelves in different Wal-Mart stores. When consumers take them off from the goods shelves, the cashier will send signals to the commodity suppliers through the network of Wal-Mart when scanning the commodities. After suppliers receive the signals, they will supplement commodities to the distribution center of Wal-Mart according to the above supply chain. This process goes round and round.

Therefore, when you take off a commodity from the goods shelf of Wal-Mart, the commodity will be produced in a certain place around the world. Wal-Mart conducts horizontal cooperation among suppliers, retailers and consumers through the "supply chaining" mode. In this way, it can timely grasp the latest demands of consumers in the era of consumer demand diversification—shortage can always make more profits than surplus. Someone might consider that this is an effective marketing method of Wal-Mart, but it's not true. Such a new retailer operation mode contains the quintessence of scope economy. It has integrated suppliers, logistics transportation and customers into its marketing, and formed an uncrossed low-cost supply chain. Firstly, Wal-Mart requires its commodity suppliers to install specific bar codes and electronic supply systems according to its specifications, so as to effectively reduce the transaction cost with suppliers and to improve veracity and efficiency of freight delivery. Secondly, for Wal-Mart, each commodity can be acquired from the same wholesaler, so it has to directly purchase commodities from manufacturers if it wants to gain a lower purchase price than other retailers. However, it is impossible for manufacturers to send commodities to various Wal-Mart stores. Therefore, Wal-Mart has established its own logistics distribution center. The average cost of operating distribution 
center is increased, but the cost of wholesaler link is saved. As a result, the ultimate cost of Wal-Mart is reduced. Meanwhile, by sharing commodity information with suppliers, Wal-Mart can effectively save cost and avoid overstock. Moreover, it can acquire the latest consumer demand information in time. All in all, when the supply chain scale and scope are larger, they are able to sell products to consumers at a lower price. Besides, there will be more advantages in the process of bargaining with suppliers, and thus bigger benefit can be acquired.

\subsection{Demanders}

Commodity suppliers will benefit from such scope economy. Besides, consumer demand has provided powerful support for scope economy when it plays a role in the current economic society. The US scholar Chris Anderson [11] narrated the era faced by us as consumers in The Long Tail. Transfer of our cultural and economic centers is accelerated, and it moves from few big hotspots (mainstream products and markets) at the head of the curve to a large number of niche products and markets at the tail of the curve. In an era without commodity space limitation and other supply bottlenecks, products and services directing at small groups can have the same economic attraction as mainstream hotspots. This means that we consumers possess more diversified and individualized choices, which are not restricted to standardized products from large-scale production several decades ago. Such changes mainly depend on the following three aspects. 1) Expansion of selection space: with the development of production technology, producers have already been transformed from enterprises and factories into individuals, and various products are manufactured all the time. Therefore, our selection space is expanded at an unprecedented speed, and the camp of selectable products multiplies. 2) Reduction of search cost: nowadays, internet makes consumers able to hunt for any products they need as well as products with more individualized characteristics. Through online shopping, consumers can acquire thousands of commodities easily. 3) Flexible production mode: advanced production technology makes individualized products possible. Through 3D print technology and reconfigurable production system, consumers can acquire customized products. For instance, when consumers purchase a computer in HP store, the workers can customize an exclusive computer for them within 2 - 3 days as long as they tell them their requirements for computer configuration and functions.

All these will promote consumers to pursue differentiated commodities and make the commodity life cycle shorter and shorter. The quick change of consumer demand market will raise a new requirement for suppliers again. Only by establishing an individualized product supply chain able to rapidly respond to the market and timely satisfy consumers, can enterprises maintain economic growth ability in the third industrial revolution. Without question, scope economy plays a unique role in effectively reducing the cost by utilizing the synergistic effect among different industries, and manufacturing individualized products by rapidly responding to the market.

\section{Conclusive Comments}

In the tide of the third industrial revolution, in order to prosper the industry, western developed countries will vigorously promote the global industrial production system to change toward the direction of digitization, individualization and intelligence that will help to express the advanced manufacturing technology advantage of developed countries. Developing countries like China are faced with impacts and challenges like gradual weakening of labor cost advantage, localization and decentralization of production mode, increasing deepening of service degree in manufacturing industry, and suppression on the traditional industry upgrading path, so paradigm change of traditional manufacturing industry becomes an increasingly significant topic. With the appearance of flexible production mode covering 3D print technology and reconfigurable production system, average cost curve of enterprise production will become a horizontal line, and there will be no difference between the single finished product and finished product batch. As a result, scale economy does not have an obvious effect on cost reduction. In addition, with the saturation of traditional commodity market, consumers' individualized needs are more prominent. Standardized products from mass production cannot adapt to consumer demands anymore. In the modern market where product cycle is shortened and consumer demands change with each passing day, individualized customized production dominated by scope economy is undoubtedly more suitable. It can respond to the market requirements quickly and satisfy consumers' individualized needs.

However, this does not mean that scale economy is not applicable. In my opinion, this is an economic thought and manufacturing paradigm transformation toward scope economy on the basis of scale economy-large-scale individualized customization. We should not totally repudiate scale economy when emphasizing quick response 
to the market and demand diversification. Its effect on product cost reduction is not obvious, but it still plays a role in reducing enterprise operation cost.

Therefore, when the third industrial revolution becomes even more violent, China has to effectively combine the thought of scope economy with transformation of traditional manufacturing paradigm by directing at different market requirements. Besides, the combination between digital manufacturing industry and informatization should be promoted, and the application of advanced manufacturing technology must be valued, so as to grasp the development opportunity. We must enter the so-called list of developed countries, rather than fall behind them again.

\section{References}

[1] Ricardo, D. (1981) On the Principles of Political Economy and Taxation: The Works and Correspondence of David Ricardo. Cambridge University Press., Cambridge

[2] Huang, Y.H. and Zhuo, L.H. (2013) "Re-Industrialization" Strategy of the US and the Third Industrial Revolution. Chinese Cadres Tribune, 10, 23-26.

[3] Rifkin, J. (2011) The Third Industrial Revolution: How Lateral Power Is Transforming Energy, the Economy, and the World. Palgrave Macmillan, London, 5-15

[4] Xing, H.F. and Markillie, P. (2012) The Third Industrial Revolution. World Science, No. 7, 10-15.

[5] Huang, Q.H. (2013) How China Tackles Challenges of the Third Industrial Revolution. Chinese Cadres Tribune, 10, 15-18.

[6] Feng, F. (2013) The Third Industrial Revolution Is the Important Change of Production and Life Styles. Chinese Cadres Tribune, 10, 11-14.

[7] Huang, Q.H. and He, J. (2013) China's Industrialization Process under the Background of "the Third Industrial Revolution" and "Manufacturing Industry Servicizing”. Globalization, No. 1, 97-104

[8] Sun, B.L. (2013) Ten Questions of the Third Industrial Revolution. Automation Panorama, No. 1, 12-18.

[9] Shen, Q.Q. (2011) Literature Review about Scope Economy. Modern Business Trade Industry, No. 3, 57-58.

[10] Friedman, T.L. (2008) The World Is Flat: A Brief History of the Twenty-First Century: Content Upgrading and Expansion Version. He, F., Xiao, Y.Y. and Hao, Z.F., Trans., Hunan Science and Technology Press, Changsha.

[11] Anderson, C. (2012) The Long Tail. Qiao, J.T. and Shi, X.Y., Trans., CITIC Press Group, Beijing. 